\title{
Background and Clinical Knowledge of Intimate Partner Violence: A Study of Primary Care Residents and Medical Students at a United States Medical School
}

\author{
Margaret Carlson,, Akiko Kamimura,,* Sarah Al-Obaydi, Ha Ngoc Trinh, and Kathy Franchek-Roa ${ }^{3}$
}

\begin{abstract}
Purpose: Intimate partner violence (IPV) is a significant public health issue that affects the physical and mental health of victims. However, residents and medical students may not receive adequate training to effectively identify and intervene with patients who may be victims of IPV. The purpose of this study is to examine the background and clinical knowledge of IPV among primary care residents and medical students in the United States of America.

Methods: Third and fourth year medial students $(n=65)$ and primary care residents $(n=60)$ participated in an online survey in 2013.

Results: While the majority of the participants reported IPV was an important and relevant issue for their practice, approximately half of them had never talked about IPV with patients. Residents reported higher levels of background and knowledge of IPV than medical students. Knowing a victim of IPV, confidence about talking to patients about IPV, and talking to patients about IPV would be helpful to increase levels of background and knowledge of IPV.

Conclusions: This study found that background and clinical knowledge of IPV can potentially affect physicians' approach with IPV victims. This study also demonstrated the need for future research in the development of effective programs and trainings to help bridge the gap between knowledge and implementation in medical practice.
\end{abstract}

Keywords: intimate partner violence; medical education; postgraduate medicine; USA

\section{Introduction}

One of the most common forms of violence against women in the United States (U.S.) is intimate partner violence (IPV). ${ }^{1}$ IPV is a significant, yet preventable, public health issue. According to the Centers for Disease Control and Prevention (CDC), IPV involves physical, sexual, and/or psychological abuse and violence by a current or former partner or spouse ${ }^{2}$ and is used to establish power and control in a relationship. ${ }^{3}$ Intimate partner violence is common in heterosexual relationships, with up to one in three women reporting a history of IPV victimization at some point in their lives. ${ }^{4}$

\footnotetext{
${ }^{1}$ Department of Sociology, University of Utah, Salt Lake City, Utah.

${ }^{2}$ Center for Interdisciplinary Research in Women's Health, University of Texas Medical Branch, Galveston, Texas.

${ }^{3}$ Department of Pediatrics, School of Medicine, University of Utah, Salt Lake City, Utah.

*Address correspondence to: Akiko Kamimura, PhD, MSW, MA, Department of Sociology, University of Utah, 380 S 1530 E, Salt Lake City, UT 84112 , E-mail: akiko .kamimura@utah.edu

(c) Margaret Carlson et al. 2017; Published by Mary Ann Liebert, Inc. This is an Open Access article distributed under the terms of the Creative Commons Attribution License, which permits unrestricted use, distribution, and reproduction in any medium, provided the original work is properly cited. Mary Ann Liebert, Inc. offers reprint services for those who want to order professionally produced copies of articles published under the Creative Commons Attribution (CC BY) license. To obtain a price quote, email Reprints@liebertpub.com. Please include the article's title or DoI, quantity, and delivery destination in your email.
} 
Strong evidence exists that links IPV victimization with adverse health outcomes ${ }^{2,5,6}$ including physical (e.g., cardiovascular disease, chronic pain syndromes, gastrointestinal disorders, central nervous system disorders, asthma, and bladder and kidney infections), ${ }^{7}$ and mental health problems (e.g., depression, anxiety, post-traumatic stress disorder). ${ }^{8}$ Female victims of IPV and their children seek healthcare services more often than females who are not victims of IPV ${ }^{9}$; however, victims rarely disclose IPV victimization and are rarely asked by healthcare providers. ${ }^{10}$ In addition, even when healthcare providers ask about IPV, victims may not disclose their abuse due to a variety of reasons including fear of further harm, loss of their children, arrest of their perpetrator, and previous poor response by a healthcare provider. ${ }^{11}$

For the most part, all American medical schools had implemented some form of IPV training in their medical school curriculum ${ }^{12}$ and screening practices for physicians. ${ }^{13}$ In 2013, the U.S. Preventive Services Task Force (USPSTF) recommended that all clinicians screen all women of child bearing age for IPV victimization and provide intervention services for those who screen positive. ${ }^{14}$ Despite these evidence-based recommendations, many clinicians still do not routinely screen women for IPV victimization. ${ }^{15}$ Common barriers to clinician screening for IPV include time constraints, a lack of resources, and inadequate training on the subject. ${ }^{15,16}$

There are published studies that provide information about how to educate healthcare providers to identify and intervene with victims of IPV. ${ }^{17}$ Frank et al. found that medical students who did not receive IPV training as compared with those who did, were less likely to screen for IPV and thus were less likely to provide adequate intervention and resources. ${ }^{18}$ Since IPV has significant impacts on the health and well-being of victims, studying the optimal methods of IPV training and education for healthcare providers is essential in preparing future physicians to adequately address this issue in the healthcare setting. ${ }^{19}$

The purpose of this study is to examine the background and clinical knowledge of IPV among primary care residents (residents in internal medicine, family medicine, pediatrics, and obstetrics/gynecology) and medical students at one medical school in the U.S. Examining the attitudes toward and perceptions of IPV among medical students and residents is crucial in understanding the gaps between knowledge and practice that may hinder the ability to address issues of IPV with patients.

\section{Methods}

\section{Data collection and study participants}

The cross-sectional data were collected from June to September 2013 at one public medical school in the U.S. At this medical school, medical students are required to take a two-semester course that includes psychosocial issues relevant to medicine, including IPV education, in the first and second years. Primary care residents (i.e., internal medicine and pediatrics) are required to take a half-day IPV education course usually during their intern year and then utilize the knowledge and skills obtained in the clinic and hospital setting. Before data collection, this study was approved as an exempt protocol by the Institutional Review Board of that University. Consent was obtained from each participant before starting the survey. In June 2013, primary care residents (pediatrics, family medicine, internal medicine, and obstetrics/ gynecology) received an email with a link to an online survey. In July 2013, third- and fourth-year medical students received an email with a link to an online survey. The online survey continued until September 2013 including a reminder email that was sent out in September 2013.

\section{Measures}

Demographics

Standard demographic questions regarding sex and age were developed. The participants were also asked whether they had heard about or witnessed IPV in the community, and whether they knew anyone personally who had experienced IPV.

\section{Training in IPV and experience with patients}

Five questions about training were taken from Frank et al. ${ }^{18}$ : [e.g., "How much training have you had in IPV during medical school and residency?" (threepoint Likert scale: $1=$ none, $2=$ some, $3=$ extensive)]

\section{Background and clinical knowledge about IPV}

Two sections to measure knowledge about IPV were extracted from a tool for evaluating physician readiness to manage IPV, which is known to have good reliability. ${ }^{20}$ The first section "background knowledge" determines current IPV background knowledge of participants, and includes 16 items on a seven-point Likert scale $(1=$ nothing, $7=$ very much). Scoring was based on a mean. Higher scores indicate higher levels of background knowledge about IPV. 
The second section used two types of questions (four multiple choice and 11 true/false statements) to determine how knowledgeable the participants were about IPV, and included two sets of questions. The first set included four multiple choice questions with multiple answers (e.g., "Which of the following are warning signs that a patient may have been abused by her partner?"). The second set of questions included 11 true/false statements (e.g., "Alcohol consumption is the greatest single predictor of the likelihood of IPV"). Scoring was based on the number of correct answers.

\section{Data analysis}

Data were analyzed using Statistical Package for the Social Sciences Version 22 (IBMCorp, Armonk, NY, USA). Descriptive statistics were used to describe the distribution of demographic characteristics of participants and opinions about and training in IPV. Descriptive data are presented as proportions for categorical variables, means with standard deviations (SDs) for continuous variables, and frequencies and percentages for categorical variables. Independent samples $t$-tests were used to compare mean of background knowledge and clinical knowledge about IPV between residents and medical students. Multiple regression analysis was conducted to predict levels of clinical or background knowledge in IPV. Individual characteristics (female sex, witnessed/heard about IPV in the community, know an IPV victim) that may affect levels of clinical and background knowledge were also added. Other measures that do not have a standardized way to quantify as a single measure were not included in the regression analysis, but were used to describe the participants' attitudes toward IPV and training. Regression coefficients with standard errors were reported to obtain a $95 \%$ confidence interval.

\section{Results}

Table 1 describes the demographic characteristics of the participants. The response rate was $37.5 \%(60 /$ 160) for medical students and $26.7 \%(65 / 243)$ for residents. More than $60 \%$ of the participants were between 25 and 30 years old, most were white $(87 \%)$, and almost three-quarters $(70 \%)$ were in internal medicine or pediatrics. The majority (78.4\%) of residents and medical students had heard about or witnessed IPV in the community and knew of someone who had experienced IPV (56.0\%).
Table 1. Demographic Characteristics

\begin{tabular}{|c|c|c|c|}
\hline & $\begin{array}{c}\text { Total } \\
(n=125)\end{array}$ & $\begin{array}{l}\text { Residents } \\
(n=65)\end{array}$ & $\begin{array}{c}\text { Medical } \\
\text { students } \\
(n=60)\end{array}$ \\
\hline Female & $70(56.0)$ & $42(64.6)$ & $28(46.7)$ \\
\hline \multicolumn{4}{|l|}{ Age (years) } \\
\hline $20-24$ & $14(11.2)$ & 0 & $14(23.3)$ \\
\hline $25-30$ & $83(66.4)$ & $44(67.7)$ & $39(65.0)$ \\
\hline Older than 30 & $28(22.4)$ & $21(32.3)$ & 7 (11.7) \\
\hline \multicolumn{4}{|l|}{ Race/ethnicity } \\
\hline White & $109(87.2)$ & $56(86.2)$ & $53(88.3)$ \\
\hline Asian & $7(5.6)$ & $6(9.2)$ & $1(1.7)$ \\
\hline Hispanic & $6(4.8)$ & $1(1.5)$ & $5(8.3)$ \\
\hline Other & $3(2.5)$ & $2(3.0)$ & $1(1.7)$ \\
\hline $\begin{array}{l}\text { Have heard about or witnesses } \\
\text { intimate partner violence } \\
\text { in the community }\end{array}$ & $98(78.4)$ & $49(75.4)$ & 49 (81.7) \\
\hline $\begin{array}{l}\text { Know someone who has } \\
\text { experienced intimate } \\
\text { partner violence }\end{array}$ & $70(56.0)$ & $35(53.8)$ & $35(58.3)$ \\
\hline \multicolumn{4}{|l|}{ Specialty (residents only) } \\
\hline Internal medicine & & $24(36.9)$ & \\
\hline Pediatrics & & $24(36.9)$ & \\
\hline OB/GYN & & $10(15.4)$ & \\
\hline Family medicine & & $7(10.8)$ & \\
\hline
\end{tabular}

Frequency (\%).

OB/GYN, obstetrics/gynecology.

Table 2 presents the results of IPV training. The majority of residents (93.8\%) and medical students $(58.4 \%)$ had at least some training on IPV. The majority of residents and medical students were somewhat $(68.0 \%)$ or highly $(5.6 \%)$ confident about talking to

Table 2. IPV Training of Residents and Medical Students

\begin{tabular}{|c|c|c|c|}
\hline & $\begin{array}{l}\text { Total } \\
(n=125)\end{array}$ & $\begin{array}{l}\text { Residents } \\
(n=65)\end{array}$ & $\begin{array}{l}\text { Medical } \\
\text { students }(n=60)\end{array}$ \\
\hline \multicolumn{4}{|c|}{ How much training have you had on IPV during medical school? } \\
\hline None & $29(23.2)$ & $4(6.2)$ & $25(41.7)$ \\
\hline Some & $95(76.0)$ & $61(93.8)$ & $34(56.7)$ \\
\hline Extensive & $1(0.8)$ & 0 & $1(1.7)$ \\
\hline \multicolumn{4}{|c|}{ How confident are you about talking to patients about IPV? } \\
\hline Not at all & $33(26.4)$ & $16(24.6)$ & $17(28.3)$ \\
\hline Somewhat & $85(68.0)$ & $47(72.3)$ & $38(63.3)$ \\
\hline Highly & $7(5.6)$ & $2(3.1)$ & $5(8.3)$ \\
\hline \multicolumn{4}{|c|}{ How important is it for physicians to talk to patients about IPV? } \\
\hline Not at all & 0 & 0 & 0 \\
\hline Somewhat & $18(14.4)$ & $11(16.9)$ & $7(11.7)$ \\
\hline Highly & 107 (85.6) & $54(83.1)$ & $53(88.3)$ \\
\hline \multicolumn{4}{|c|}{ How relevant do you think IPV will be in your intended practice? } \\
\hline Not at all & $9(7.2)$ & $3(4.6)$ & $6(10.0)$ \\
\hline Somewhat & $78(62.4)$ & $45(69.2)$ & $33(55.0)$ \\
\hline Highly & $38(30.4)$ & $17(26.2)$ & $21(35.0)$ \\
\hline \multicolumn{4}{|c|}{$\begin{array}{l}\text { With a typical general medicine patient, how often do you talk to } \\
\text { patients about IPV? }\end{array}$} \\
\hline Never/rarely & $65(52.0)$ & $32(49.2)$ & $33(55.0)$ \\
\hline Sometimes & $52(41.6)$ & $29(44.6)$ & $23(38.3)$ \\
\hline Usually/always & $8(6.4)$ & $4(6.2)$ & $4(6.7)$ \\
\hline
\end{tabular}

Frequency (\%).

$\mathrm{IPV}$, intimate partner violence. 
Table 3. Background and Clinical Knowledge of Intimate Partner Violence

\begin{tabular}{lrrcc}
\hline & \multicolumn{1}{c}{ Total } & \multicolumn{1}{c}{ Residents } & Medical students & $\boldsymbol{F}$ \\
\hline Background $^{* *}$ & $3.48(1.20)$ & $3.77(1.02)$ & $3.17(1.31)$ & 2.34 \\
Clinical** $^{*}$ & $21.54(3.73)$ & $22.94(2.65)$ & $20.02(4.13)$ & 6.11 \\
\hline
\end{tabular}

Mean (SD).

Independent sample $t$-tests ${ }^{*} p<0.01$

Higher score indicates higher levels of background or knowledge of intimate partner violence.

$\mathrm{SD}$, standard deviation.

patients about IPV, and somewhat $(62.4 \%)$ or highly (30.4\%) believe IPV would be relevant in their practice. Although all of the participants believed it is somewhat or highly important for physicians to talk to patients about IPV, only about half (50.8\% residents; $45.0 \%$ medical students) had ever talked to a patient about IPV.

Table 3 shows the results of independent sample $t$ tests on the medical students' and residents' background and clinical knowledge about IPV. Residents reported higher levels of background (residents: mean $=3.77, \mathrm{SD}=1.02$; medical students: mean $=3.17$, $\mathrm{SD}=1.31 ; F=2.34$ ) and clinical knowledge of IPV (residents: mean $=22.94, \mathrm{SD}=2.65$; medical students: mean $=20.02, \mathrm{SD}=4.13) ; F=6.11$ ) compared to medical students. Table 4 summarizes the results of regression analysis on the predictors of higher scoring of background and clinical knowledge of IPV. Predictors for higher scoring on background knowledge included being a resident $(\beta=0.55, p<0.01)$, knowing a victim $(\beta=0.39, p<0.05)$, feeling confident in talking to

Table 4. Regression Analysis on Background and Clinical Knowledge of Intimate Partner Violence

\begin{tabular}{|c|c|c|c|c|}
\hline Dependent variables & Background $^{\mathrm{a}} \beta$ & pe & Clinical $\beta$ & $p$ \\
\hline \multicolumn{5}{|l|}{ Independent variables } \\
\hline Residents $^{\mathrm{b}}$ & 0.55 & $<0.01$ & 2.66 & $<0.01$ \\
\hline Female & 0.16 & N.S. & 1.61 & $<0.05$ \\
\hline Witnessed/heard about IPV & 0.37 & N.S. & 0.30 & N.S. \\
\hline Know a victim of IPV & 0.39 & $<0.05$ & 0.05 & N.S. \\
\hline $\begin{array}{l}\text { Confident about talking } \\
\text { to patients about IPV }\end{array}$ & 1.02 & $<0.01$ & 1.89 & $<0.01$ \\
\hline $\begin{array}{l}\text { Talk to patients about IPV } \\
\text { sometimes/usually/always }\end{array}$ & 0.48 & $<0.05$ & -1.26 & $=0.05$ \\
\hline (Constant) & 1.62 & $<0.01$ & 18.21 & $<0.01$ \\
\hline$R^{2}$ & 0.37 & & 0.25 & \\
\hline$F$ & 11.76 & & 6.69 & \\
\hline$p$ & $<0.01$ & & $<0.01$ & \\
\hline
\end{tabular}

${ }^{\mathrm{a}}$ Higher score indicates higher levels of background or knowledge of intimate partner violence.

${ }^{\mathrm{b}}$ Reference group $=$ medical students. patients about IPV $(\beta=1.02, p<0.01)$, and at least sometimes talking to a patient about IPV $(\beta=0.48, p<0.05)$. Predictors for increased clinical knowledge about IPV included being a resident $(\beta=2.66, p<0.01)$, being female $(\beta=1.61, p<0.05)$, and feeling confident about talking to patients about IPV $(\beta=1.89, p<0.01)$.

\section{Discussion}

This study examined background and clinical knowledge of IPV among residents and medical students in the U.S. There are three main findings. First, while the majority of the participants reported IPV was an important and relevant issue for their practice, approximately half of them had never talked about IPV with patients. Second, residents reported higher levels of background and clinical knowledge of IPV than medical students. Third, knowing a victim of IPV, confidence about talking to patients about IPV, and actually talking to patients about IPV were associated with higher scoring in background and clinical knowledge of IPV.

The results of this study suggest residents and medical students need to talk about IPV with patients, whenever it is relevant, because while the majority of the participants reported IPV was an important and relevant issue for their practice, approximately half of them had never talked about IPV with patients. IPV training for healthcare providers increases the knowledge and efficacy for dealing with IPV-related issues. ${ }^{21}$ But increasing knowledge is not enough. A previous study found that family physicians do not feel comfortable discussing IPV-related issues with patients. ${ }^{22}$ It is necessary to provide education focusing on communications with patients and knowledge regarding IPVrelated topics.

Residents have more knowledge than medical students. Primary care residents may have potentially more opportunities to receive IPV training or the quality of IPV training for residents may have been improved. Medical students probably receive only general education about IPV compared to residents in primary care. While the amount of hours that family medicine residents receive violence education has not necessarily increased, active learning strategies have been used more often than before. ${ }^{23}$ The active learning strategies may be implemented for medical education and improve the knowledge about IPV among medical students.

The results of this study show that, in addition to education, the following factors would be helpful in 
increasing levels of background and clinical knowledge of IPV: knowing a victim of IPV; confidence about talking to patient about IPV; and talking to patients about IPV. Education strategies that include opportunities for residents and medical students to actually interact with IPV victims would be more effective than those based on classroom settings or online courses. ${ }^{24}$ The results of this study confirm that actual interactions with IPV victims are very important for residents and medical students to better serve patients who have been victims of IPV.

While this study provides useful information on IPV education for primary care residents and students, there are limitations. This is a cross-sectional study and therefore does not determine causal relationships between the variables. The small number of participants, who were from one university, limits generalizability. Moreover, lack of diversity among the study participants inhibits the generalizability of this study. In addition, there may have been potential selection bias in that it is possible that residents or students with an interest in IPV may have been more likely to participate in the survey.

\section{Conclusions}

This study described the background and clinical knowledge about IPV among residents and medical students in the U.S. The results of this study show that background and clinical knowledge of IPV potentially affect physicians' approach with their patients. This study also demonstrated the need for future research to identify strategies to bridge the gap between knowledge and implementation in medical practices. Because IPV is a significant medical issue, medical professionals, both current and future, need to know how to identify and effectively intervene with patients who have experienced IPV victimization.

\section{Acknowledgments}

Dr. A.K. had full access to all of the data in the study and takes responsibility for the integrity of the data and the accuracy of the data analysis. The study concept and design were by Drs. A.K., S.A.O., H.N.T., and K.F.R. Acquisition of data was by Drs. A.K. and K.F.R. Drafting of the article was by Ms. M.C. and Dr. A.K. Interpretation of data and critical revision of the article for important intellectual content was done by all authors. Statistical analysis was by Dr. A.K. Administrative, technical, or material support was by A.K. Study supervision was by Dr. A.K. and
Dr. K.F.R. Ms. M.C. was supported by the Undergraduate Research Opportunities Program, University of Utah. This study was partially supported by the College of Social and Behavioral Science, University of Utah (Dr. A.K.). The authors wish to thank the study participants and would like to acknowledge the contributions of Drs. James Bale, Evelyn Gopez, Sonja Van Hala, Caroline Milne, Adam Stevenson, and Stephanie Wilder.

\section{Author Disclosure Statement}

No competing financial interests exist.

\section{References}

1. Breiding MJ, Smith SG, Basile KC, et al. Prevalence and Characteristics of Sexual Violence, Stalking, and Intimate Partner Violence VictimizationNational Intimate Partner and Sexual Violence Survey, United States, 2011. MMWR Surveillance Summaries. 2014;63:1-18.

2. Center for Disease Control and Prevention. Intimate Partner Violence. Available at:www.cdc.gov/violenceprevention/intimatepartnerviolence Accessed February 23, 2017.

3. Burge SK, Katerndahl DA, Wood RC, et al. Using complexity science to examine three dynamic patterns of intimate partner violence. Fam Syst Health. 2016;34:4-14.

4. Black MC, Basile KC, Breiding MJ, et al. The National Intimate Partner and Sexual Violence Survey: 2010 Summary Report. Atlanta, Georgia: Center for Disease Control and Prevention; 2011.

5. Campbell J, Jones AS, Dienemann J, et al. Intimate partner violence and physical health consequences. Arch Intern Med. 2002;162:11571163.

6. Goodman PE. The relationship between intimate partner violence and other forms of family and societal violence. Emerg Med Clin North Am. 2006;24:889-903.

7. Dutton MA, Green $\mathrm{BL}$, Kaltman $\mathrm{SI}$, et al. Intimate partner violence, PTSD, and adverse health outcomes. J Interpers Violence. 2006;21: 955-968.

8. Afifi TO, MacMillan H, Cox BJ, et al. Mental Health correlates of intimate partner violence in marital relationships in a nationally representative sample of males and females. J Interpers Violence. 2009;24: 1398-1417.

9. Rivara FP, Anderson ML, Fishman $\mathrm{P}$, et al. Healthcare utilization and costs for women with a history of intimate partner violence. Am J Prev Med. 2007;32:89-96.

10. Sprague S, Madden K, Simunovic N, et al. Barriers to screening for intimate partner violence. Women Health. 2012;52:587-605.

11. Gerbert B, Moe J, Caspers N, et al. Topic in review - Simplifying physicians' response to domestic violence. West J Med. 2000;172:329-331.

12. Hamberger LK. Preparing the next generation of physicians: medical school and residency-based intimate partner violence curriculum and evaluation. Trauma Violence Abuse. 2007;8:214-225.

13. Zink T, Regan S, Goldenhar L, et al. Intimate partner violence: what are physicians' perceptions? J Am Board Fam Med. 2004;17:332-340.

14. U.S. Preventive Services Task Force (USPSTF). Recommendations. Available atwww.uspreventiveservicestaskforce.org/Page/Name/uspstf-a-andb-recommendations Accessed February 23, 2017.

15. Paterno MT, Draughon JE. Screening for intimate partner violence. J Midwifery Womens Health. 2016;61:370-375.

16. Sormanti $M$, Smith $E$. Intimate partner violence screening in the emergency department: U.S. medical residents' perspectives. Int Q Community Health Educ. 2010;30:21-40.

17. Rhodes KV, Drum M, Anliker E, et al. Lowering the threshold for discussions of domestic violence- A randomized controlled trial of computer screening. Arch Intern Med. 2006;166:1107-1114.

18. Frank E, Elon L, Saltzman LE, et al. Clinical and personal intimate partner violence training experiences of US medical students. J Women Health. 2006;15:1071-1079. 
19. Garimella R, Plichta SB, Houseman C, et al. Physician beliefs about victims of spouse abuse and about the physician role. J Womens Health Gend Based Med. 2000;9:405-411.

20. Short LN, Alpert E, Harris JM, et al. A tool for measuring physician readiness to manage - Intimate partner violence. Am J Prev Med. 2006;30:173-180.

21. Edwardsen EA, Horwitz SH, Pless NA, et al. Improving identification and management of partner violence: examining the process of academic detailing: a qualitative study. BMC Med Educ. 2011;11:36.

22. Pagels $P$, Kindratt TB, Reyna $G$, et al. Establishing the need for family medicine training in intimate partner violence screening. J Community Health. 2015;40:508-514.

23. Cronholm PF, Singh V, Fogarty $\mathrm{CT}$, et al. Trends in violence education in family medicine residency curricula. Fam Med. 2014;46:620-625.

24. University of California, Davis. 5-step experiential learning cycle definitions. Available at www.experientiallearning.ucdavis.edu/module1/ el1_40-5step-definistion.pdf Accessed February 23, 2017
Cite this article as: Carlson M, Kamimura A, Al-Obaydi S, Trinh HN Franchek-Roa K (2017) Background and clinical knowledge of intimate partner violence: a study of primary care residents and medical students at a United States medical school, Health Equity 1:1, 77-82, DOI: 10.1089/heq.2017.0008.

$\begin{aligned} & \text { Abbreviations Used } \\ & \mathrm{IPV}= \text { intimate partner violence } \\ & \mathrm{OB} / \mathrm{GYN}=\text { obstetrics/gynecology } \\ & \mathrm{USPSTF}=\text { U.S. Preventive Services Task Force }\end{aligned}$

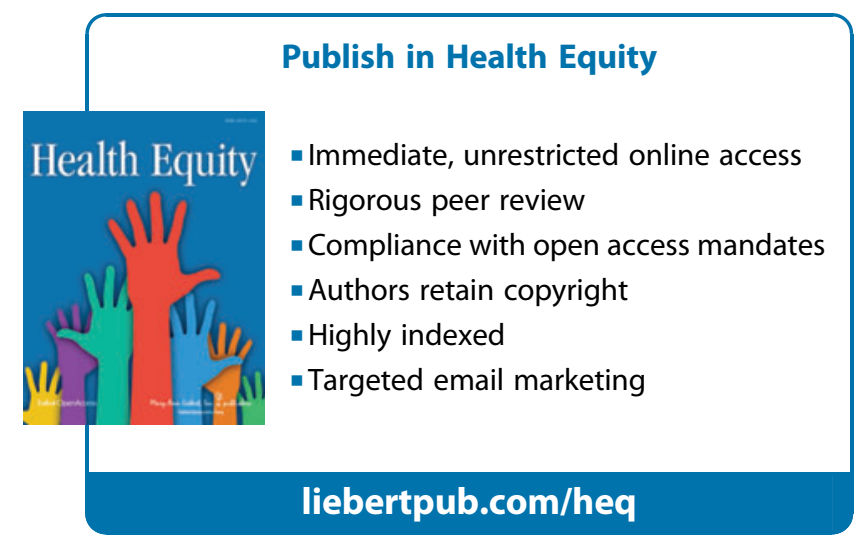

